\title{
Erratum to: In vitro shoot organogenesis and plant regeneration in Tibouchina aspera Aubl.
}

\author{
Xinhua Zhang ${ }^{1} \cdot$ Seping Dai ${ }^{2} \cdot$ Jaime A. Teixeira da Silva ${ }^{3} \cdot$ Guohua Ma $^{1}$
}

Published online: 21 July 2015

(C) The Society for In Vitro Biology 2015

Erratum to: In Vitro Cell.Dev.Biol.-Plant

DOI 10.1007/s11627-015-9691-Z

The metadata for the third author's name was incorrect. The correct Given Name is Jaime A. and the correct Family Name is Teixeira da Silva.

The online version of the original article can be found at http://dx.doi.org/ 10.1007/s11627-015-9691-z.

\footnotetext{
Jaime A. Teixeira da Silva

jaimetex@yahoo.com

$\bowtie$ Guohua Ma

magh@scib.ac.cn
}

1 Key Laboratory of Plant Resources Conservation and Sustainable Utilization, South China Botanical Garden, Chinese Academy of Sciences, Guangzhou 510650, People's Republic of China

2 Guangzhou Institute of Landscape Garden, Guangzhou 510405, People's Republic of China

3 P. O. Box 7, Miki-cho post office, Ikenobe 3011-2, Kagawa-ken 761-0799, Japan 